to, that which I described a few years ago ${ }^{2}$. If a fine jet of water issuing from a fine nozzle with a moderate velocity reaches the surface of tap or distilled water in its instability range, it is resolved into many floating drops which last about three seconds. I noticed that the chief condition for the success of the experiment was the freshness and cleanness of the water used. Even the least trace of grease, for example, the very touch of the surface with the fingers, lessened the range and life of the drops, or even made success impossible. In so far as the same phenomenon is in question, the interpretation of the above-mentioned authors is opposed to these observations of mine.

Physies Institute,

$$
\begin{gathered}
\text { University of Zagreb, } \\
\text { Jugoslavia. } \\
\text { Oct. } 16 .
\end{gathered}
$$

1. I. W. Wark and A. B. Cox, NATURE, 136, 182, A ugnst 3, 1935. \&. Kataliníe, Nature, 127, 627, April 25, 1931 .

\section{Cytoplasmic Bodies in the Oogenesis of Lumbricus}

By those ${ }^{1}$ who have worked on the oogenesis of Lumbricus or allied forms, the vitellogenesis is believed to be one of the simplest known, though there is no general agreement.

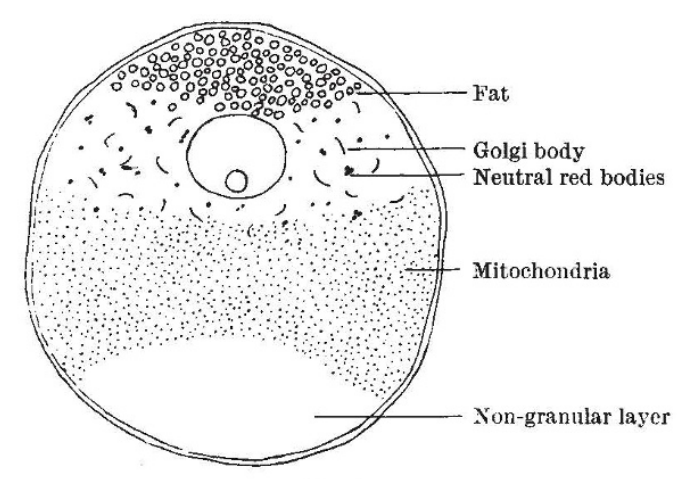

FIG. 1.

We have recently used the Beams' ultra-centrifuge on these eggs, and our findings are as follow. The eytoplasmic granules form a number of layers, consisting of fat granules above, Golgi elements below and in the region of the nucleus, mitochondria lower still, and the lowermost layer formed of a homogeneous and non-granular substance, as shown in the semi-diagrammatic reproduction (Fig. 1). The mitochondria are granular, not filamentous. No protein yolk could be found, and the larger granules to be seen so clearly in the living eggs are fat, not Golgi bodies; when previously stained supra-vitally in neutral red, before centrifuging, the globules so produced take up a position mainly between the fat and the mitochondria, that is the region where the dictyosomes of the Golgi apparatus come to lie.

GERTRUde NoRMINTON.

Dept. Zoology,

J. Brontë Gatenby.

Trinity College, Dublin. Nov. 2. 'Harvey, Quart. J. Micr. Sci., 74; 1931. Gatenby and Nath,
Quart. J. Micr. Sci., 70; 1926. Nath, Quart. J. Micr. Sci., 73; 1930. Weiner, Z. mikr. anat. Forsch., 20; 1930.

\section{Age of the Universe}

Sir James Jeans has recently pointed out ${ }^{1}$ that observations of binary stars indicate $10^{13}$ years as the order of age of the universe, while the recession of the nebulæ, indicated by their spectral shift, suggests an age of the order of $10^{10}$ years.

In a recent publication ${ }^{2}$, however, we have shown how the spectral shifts may be accounted for by a variation with time of certain electrical and quantum quantities; this allows a way out of the difficulty. In order to measure times over long periods, one must define a standard for measuring time intervals at different epochs; such a standard might depend either on gravitational or electrical measurements, and the two systems, though by definition agreeing now, might differ in the results for a period of time in the past. Thus the age of the universe might well be $10^{13}$ years when measured in terms of a gravita. tional definition of the year, and at the same time $10^{10}$ years when measured in terms of an electrical definition of the year. The apparent discrepancy now becomes a way of determining the relative values of electrical and gravitational phenomena in the past.

The University, J. A. Chalmers. Durham.

Sir John Cass Technical Institute, Bruce Chalmers. London.

1 J. H. Jeans, NATURE, 136, 432, Sept. 14, 1935

J. A. Chalmers and B. Chalmers, Phil. Mag., 19, $436 ; 1935$.

\section{The Spectrum of $\gamma$ Cassiopeiæ}

ON and since October 7 , a very strong and very sharp absorption line, the strongest and sharpest absorption line in the whole spectrum, suddenly appeared in the spectrum of $\gamma$ Cassiopeiæ. This line is nearly coincident in position with that which should be occupied by the bright violet component of $\mathrm{H} \zeta$. On receiving this information, Prof. A. Fowler has sixggested that it is probably the neutral line of helium $(\lambda 3888 \cdot 646)$ intensity 10 , this line being the strongest line of the principal series of the triplet system. The next line in this series is at $\lambda 3187 \cdot 743$ (intensity 8 ), but this falls outside the region photographed at Sidmouth, so its presence cannot be ascertained.

In view of the other important changes in the spectrum to which I have recently directed attention, the spectrum evidently needs careful watching for further variations.

\section{Norman Lockyer Observatory,}

WrLLIAM J. S. LOCKYER. Sidmouth. Nov. 24.

\section{Fossil Human Occipital Bone from Thames Gravels}

UNDER "News and Views" in NATURE of October 19, page 638 , the discovery at Swanscombe of a human skull fragment by Mr. Marsden is recorded and the note says, inter alia, "The bone was associated with Acheulean flint implements". We should like to put on record that in our experience the middle gravel of the $100-\mathrm{ft}$. terrace, in which the bone was found, contains, in addition to Acheulean hand-axes and flake tools, artefacts of Clacton III type closely resembling those of High Lodge, and also a few flakes exhibiting a Levalloisian technique. 